the disease itself may change. They rightly suggest that a faulty mental "data base"-a term used by Weed" in his crusade for better case records-is a common cause for erroneous diagnosis. Further studies of this type would also provide evidence to grade the discriminating value of different symptoms-a useful addition for any textbook. The rating for night pain in detecting duodenal ulcer or postural heartburn for diagnosing hiatus hernia would be high. A low value might be given to nausea, aerophagy, or even loss of weight-which may not occur in cancer of the stomach but does happen in those with nervous dyspepsia. ${ }^{4}$ The clinician's problem is how to keep his mental "data base" up to date and so be ready to alter cherished notions about the clinical pictures of common disorders.

\footnotetext{
${ }^{1}$ Hinkel, C L, and Moller, G A, Gastroenterology, 1957, 32, 807.

2 Horrocks, J C, and de Dombal, F T, British Medical fournal, 1975, 3, 421

${ }^{3}$ Lucas, R W, et al, British Medical fournal, 1976, 2, 623.

' Horrocks, J C, and de Dombal, F T, Gut, 1978, 19, 19.

'Edwards, F C, and Coghill, N F, Quarterly fournal of Medicine, 1968, 37, 337.

${ }^{6}$ Weed, L L, Medical Records, Medical Education, and Patient Care.
} Chicago, Year Book Medical Publishers, 1970.

\section{Humidifier fever: a disease to look out for}

Man's ability to pollute his environment may take extremely subtle forms, and occasionally the first evidence of atmospheric contamination comes from patients with symptoms due to inhaling microscopic particles. In 1970 Banaszak et $a l^{1}$ described four patients with cough and shortness of breath apparently related to working in an office. Investigation showed them to be suffering from a form of allergic alveolitis indistinguishable from farmer's lung. ${ }^{2}$ The cause was eventually found to be the humidifier of an air-conditioner, which contained thermophilic actinomycetes whose spores were being liberated as an aerosol into the atmosphere of the office.

Subsequent reports ${ }^{3-5}$ from the United States have defined humidifier fever in greater detail. The usual presenting symptoms are cough, dyspnoea, and fever related to the season in which the air-conditioner is in use. Often-and not surprisingly - the illness may be misdiagnosed for some years. In common with allergic alveolitis from other causes it may be relatively acute or slowly progressive and chronic. This latter type is potentially serious; it is particularly difficult to recognise, and there is a real danger of progression to irreversible pulmonary fibrosis.

Air-conditioning systems are not used so widely in Britain as in the United States, but they are becoming popular in hospitals, schools, and factories. In addition to circulating air at a controlled temperature they also provide the right humidification, and to do so they require a source of water. If this water is recirculated it is often collected in a reservoir, which may provide a suitable environment for the growth of a food-chain of micro-organisms. The variety depends on factors such as the substrate available and the temperature of the water. In the warmed water typically found in American air-conditioners, thermophilic actinomycetes seem to have been the main pathogen isolated, though a host of other organisms may usually be found wherever water is allowed to stagnate. When this water is sprayed the organisms will become airborne, and those of a certain size may be inhaled.
Humidifier fever as described in Britain ${ }^{6}{ }^{7}$ seems to differ slightly from that seen in North America. The American disease is altogether similar to farmer's lung, and the patients' blood contains the corresponding precipitating antibodies (but also rheumatoid factor, often in high titre-an unexplained finding). In the British outbreaks ${ }^{s}$ patients affected were 3 workers in a rayon factory and in two separate printing and $\cong$ stationery works. Their cough, dyspnoea, fever, and malaise were worse on Mondays, improving as the week progressed. In all three factories stagnant water was used in systems that $\overline{0}$ produced an aerosol. Cellulose was abundantly available as a 흠 raw material and may have produced a suitable substrate for $\frac{\bar{T}}{\bar{D}}$

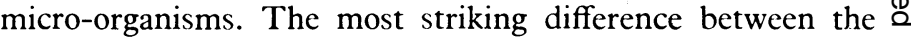
British and American outbreaks was that thermophilic क actinomycetes were not being incriminated here. While the $\overrightarrow{0}$ patients' sera contained precipitating antibodies to extracts of water or sludge these could not be shown to correspond to any of the bacteria or fungi cultured from it. The mystery has probably been solved by Edwards," who showed that the water from one outbreak was rich in protozoa and that the antibody response of the patients was to an amoeba, Naegleria $\vec{N}$ gruberi, present in the water and in settled factory dust. Subsequent investigation of the other British outbreaks has confirmed that precipitin responses to various amoebae were also present in these patients. ${ }^{8}$

Once humidifier fever is diagnosed treatment depends on avoiding exposure to the organisms. Usually changes in the humidification system, such as steam injection or avoidance $\vec{\oplus}$ of recirculation, are sufficient. The possibility of producing $\infty$ such diseases should be considered in the design of humidifying systems. The physician needs to add a new question to the history taken from patients with unexplained fever, cough, or breathlessness: "Do you have an air-conditioner or humidifier at home or work ?"

${ }^{1}$ Banaszak, E F, Thiede, W H, and Fink, J N, New England fournal of Medicine, 1970, 283, 271.

2 British Medical fournal, 1976, 1, 791.

${ }^{3} \mathrm{Fink}, \mathrm{J}$ N, et al, Annals of Internal Medicine, 1971, 74, 80.

Fink, J N, et al, Annals of Internal Medicine, 1976, 84, 406.

Burke, G W, et al, fournal of the American Medical Association, 1977, 238, 2705.

'Pickering, C A C, et al, Clinical Allergy, 1976, 6, 109.

'Friend, J A R, et al, Lancet, 1977, 1, 297.

M R C Symposium, Thorax, 1977, 32, 653

${ }^{9}$ Edwards, J H, Griffiths, A J, and Mullins, J, Nature, 1976, 264, 438.

\section{Risks of environmental exposure to asbestos}

Asbestos-related cancers are well established as an occupational hazard, but what risk is there from pollution of the general environment by asbestos fibres? As these may be both inhaled and ingested, clearly there are several possible sources of pollution.

Environmental pollution by asbestos fibres has been $\stackrel{\mathbb{Q}}{\varrho}$ recognised for over 15 years. Wagner and his colleagues, ${ }^{1}$ who $\underset{Z}{ }$ originally linked exposure to crocidolite asbestos with meso- 8 thelial tumours, found several patients who had been exposed to it only by living near the mines or playing on the mine dumps as children. In a series ${ }^{2}$ of 76 patients whe died with a $\rightleftharpoons$ mesothelial tumour at the London Hospital 11 had had no occupational or domestic exposure but had lived within half a mile of a large asbestos factory. A high incidence of pleural 